\title{
Degraded boiling heat transfer from hotwire in ferrofluid due to particle deposition
}

\author{
Ashkan Vatani ${ }^{* 1,2}$, Peter Lloyd Woodfield ${ }^{1}$, Toan Dinh ${ }^{2}$, Hoang-Phuong Phan ${ }^{2}$, Nam-Trung \\ Nguyen', Dzung Viet Dao ${ }^{1,2}$ \\ ${ }^{1}$ School of Engineering, Griffith University, Go ld Coast Campus, Gold Coast, QLD 4222, Australia \\ ${ }^{2}$ Queens land Micro- and Nanotechnology Centre, Brisbane, QLD 4111, Australia \\ * ashkan.vatani@griffithuni.edu.au
}

\begin{abstract}
Transient boiling heat transfer from an electrically-heated microwire in $\mathrm{Fe}_{3} \mathrm{O}_{4}$ /water nanofluid (ferrofluid) was investigated for the first time. The transient temperature rise of the wire for different electrical currents was measured and compared with results for deionized water to highlight the effect of the magnetic particles on the heat transfer. It was observed that below the normal boiling point of water, the ferrofluid enhances the heat transfer. However, above the boiling point, the heat transfer ability of the ferrofluid significantly decays due to deposition of particles on wire. Scanning electron microscope (SEM) images of the wire showed that the ferromagnetic particles form a coating layer on the wire of various morphologies depending on electric current and duration of heating. Parameters affecting both heat transfer and particle deposition such as current, time and concentration of ferrofluid were investigated. It was observed that the rate of particle deposition on wire and the thickness of the coating layer increases by increasing current, time and concentration of ferrofluid.
\end{abstract}

Keywords: Boiling heat transfer, Ferrofluid, Particle deposition, magnetic field, Transient hotwire

\section{Introduction}

Boiling heat transfer is considered a vital phenomenon in many industrial systems such as air conditioning, electronic cooling, food processing and power generation, where high heat transfer rates and temperature control are required. As a result of this, boiling heat transfer enhancement has been a major field of research for many years. Boiling heat transfer enhancement techniques range from surfactant addition [1] to fabrication of nanostructured extended surfaces [2]. In this study we consider the effect of the presence of ferromagnetic nanoparticles on boiling heat transfer from an electrically heated microwire.

Ferrofluid, as a novel type of cooling fluid has been proposed to enhance convection [3, 4] and boiling heat transfer $[5,6]$ when exposed to uniform or non-uniform magnetic fields. It was shown that ferrofluids, in addition to the mechanisms responsible for heat transfer enhancement of ordinary nanofluids [7], can further enhance the heat transfer when in the presence of a magnetic field. The enhancement has been mainly explained to be due to thermomagnetic convection which in addition to natural convection augments the heat transfer 
from heated surfaces. However, the effectiveness of ferrofluids for boiling heat transfer when subjected to a magnetic field is still to be confirmed. Findings of Aminfar et al [8] experimentally studied ferrofluid flow boiling in a vertical annulus in both presence and absence of magnetic field. It was shown that using ferrofluid increases the critical heat flux (CHF) up to $33 \%$ and applying a magnetic field increases the CHF a further $23 \%$, which amounts to a $56 \%$ enhancement beyond that of pure water. Habibi et al [9] achieved up to $50 \%$ enhancement to boiling heat flux by using in ferrofluid rather than pure water by applying a constant magnetic field. Abdollahi et al [10] experimentally studied the effect of a magnetic field on boiling heat transfer of ferrofluid from a flat plate. Their experiments revealed that adding the ferromagnetic nanoparticles would not necessarily augment the heat transfer coefficient. Instead, they found that surface roughness and the magnetic field gradient are the two main factors affecting the boiling heat transfer coefficient. They observed that the boiling heat transfer decreased and increased as a result of positive and negative magnetic field gradients, respectively. In a theoretical study, $\mathrm{Xu}$ and Peng [5] proposed that applying magnetic field enhances the boiling heat transfer by promoting nucleation through adsorption of high-energy fluid molecules. They also showed that by selecting optimum magnetic field intensity, the detachment diameter and detachment frequency of bubbles can be increased and decreased, respectively, to enhance the boiling heat transfer. Mohammadpourfard et al [6] numerically simulated the effect of magnetic field on pool boiling heat transfer of ferrofluid from a horizontal plate. They observed that applying a negative magnetic field gradient will elongate the bubbles and increasing the magnetic field intensity will increase the boiling heat transfer. Junhong et al [11] studied the pool boiling heat transfer of water-based magnetic fluid in absence and presence of a magnetic field. For the conditions they considered, it was shown that boiling heat transfer in a magnetic fluid increased in the absence of a magnetic field. They observed that the bubbles generated under magnetic field are smaller in size and much more in number compared to pure water. They theoretically explained their observations in terms of a magnetic buoyancy force applied to the bubbles in a magnetic field.

Deposition of nanoparticles on the heated surface and changing the surface morphology has been introduced as the main factor affecting the boiling heat transfer of nanofluids. Nabati et al [12] experimentally studied the effect of the addition of nanoparticles with different sizes on boiling heat transfer. They reported that deposition of particles with diameters smaller than the surface roughness of a clean heater makes the surface smoother, which becomes even smoother by increasing the nanoparticle concentration in the nanofluid. The result of this surface smoothness is the deterioration of heat transfer, while the story is reverse for the case of particles with larger diameter than surface roughness. These results were confirmed by experiments of Bang et al [13] where they observed enhancement to boiling heat transfer from a plain surface with nanoscale roughness. They explained that sedimentation of nanoparticles enhanced the surface roughness. In agreement with this hypothesis, Das et al [14] reported that sedimentation of nanoparticles smoothened the surface of a commercial cartridge heater with micron-scale surface finish. Manetti et al [15] concluded that the enhancement/deterioration of boiling heat transfer coefficient (BHTC) strongly depends on morphology of the surface of heater. They observed that deposition of nanoparticles increase the HTC only for low concentrations and moderate heat flux. Aminfar et al [8] claimed that the increased CHF for 
dilute nanofluid is not due to the enhanced fluid properties but as a result of nanoparticle deposition on the surface. They first measured the CHF for ferrofluid on a smooth and clean surface, and then repeated the experiment for pure water on the nanoparticle deposited surface, where similar results were obtained. They explained that deposition of nanoparticles on the heated surface by changing the contact angle and surface wettability enhanced the CHF. However, they reported that by decreasing the flow mass flux the CHF was reduced which was mainly due to attraction of nanoparticles toward the magnets and therefore reduction in deposition of nanoparticles on the heated surface.

Deposition of impurities is not only limited to nanofluids, as Hsu et al [16] studied the boiling heat transfer enhancement due to deposition of impurities of tap water. They observed that during the boiling process, deposition of impurities of tap water forms a thin film on the surface of the heater which significantly increases the critical heat flux by increasing the wettability of the surface. The effect of magnetic actuation on pool boiling heat transfer and on surface morphology of the pool was examined by Shojaeian et al [17] where up to $29 \%$ enhancement in heat transfer was achieved. It was shown that magnetic actuation significantly reduced the deposition and sedimentation of nanoparticles on the pool surface. They also observed that, although reducing the sedimentation of nanoparticles, magnetic actuation left a thick and porous film on the surface, increasing the surface roughness.

Effect of nanofluid concentration on boiling heat transfer has been investigated in numerous studies. An optimum concentration has been reported by researchers at which the heat transfer coefficient is maximised [18]. Abdollahi et al [10] observed that the pool boiling heat transfer coefficient of ferrofluid increased by increasing nanoparticle concentration up to $0.1 \%$, and then decreased by further increasing of volume concentration to $0.4 \%$. A similar trend can be seen in the results of [19]. However both groups agree that increasing concentration enhances the critical heat flux. This decrease after an optimum value of concentration was related to the formation and adherence of large clusters to nucleation sites and deactivating the nucleation sites [10]. Kole and Dey [18] simultaneously studied the effect of increasing concentration and surface roughness on boiling heat transfer. They explained that at higher concentrations, larger nanoparticle clusters that settle down at the bottom surface due to gravity cannot take part in heat transfer during the boiling process. Therefore, the actual nanoparticle concentration in the fluid decreases and results in declined heat transfer coefficients (HTCs). Moreover they added that the enhanced boiling heat transfer coefficients (BHTCs) at low nanoparticle concentration is likely due to the increased average roughness of the heater surface. In contrast at higher concentrations the thick layer of particles formed on the heater surface reduces its roughness by blocking the active nucleation sites, which in turn reduces the bubble formation intensity and consequently decreases the BHTC.

Table 1 summarises the latest studies on boiling heat transfer of magnetic fluids. Since only a limited number of studies have been done with varying results, it is clear that the effect/merit of the presence of ferromagnetic particles in the liquid for boiling heat transfer is still an open question. In particular, none of the studies in Table 1 consider heat transfer from an electrically-heated wire. This gap in the literature is an important topic for investigation since 
the electrical current through the wire produces a magnetic field which may influence the behaviour of the magnetic particles.

In the present work boiling heat transfer of ferrofluid in a non-uniform magnetic field induced around a vertically oriented current carrying wire has been experimentally studied and compared with that of deionized water (DIW). Furthermore the effect of nanoparticle deposition on the wire on the BHTC has been analysed using SEM images.

Table 1 Summary of the recent studies on boiling heat transfer of ferrofluids.

\begin{tabular}{cccc}
\hline Ref Concentration & Study type & Findings \\
\hline 17$]$ & $29 \mathrm{mg} / \mathrm{L}$ & Experimental & $\begin{array}{l}\text { Magnetic actuation of magnetic fluid enhances the BHT by } \\
\text { preventing deposition and sedimentation of particles ad also } \\
\text { assisting circulation of nanoparticles. }\end{array}$ \\
\hline
\end{tabular}

- A porous zone formed around vapor film, reduces the quenching process HT resulting in increased quenching time.

[9] $\quad 0.4-0.8 \% \mathrm{VF} \quad$ Experimental

- Implementing a magnetic field in vertical direction, produces an upward secondary current that accelerates the release of vapor bubbles and enhances the BHT up to $50 \%$.

[10] $0.01-0.4 \% \mathrm{VF}$ Experimental $\begin{aligned} & \text { - Surface roughness and magnetic field gradient are the main } \\ & \text { factors determining whether adding nanoparticles would } \\ & \text { enhance or deteriorate BHT. }\end{aligned}$

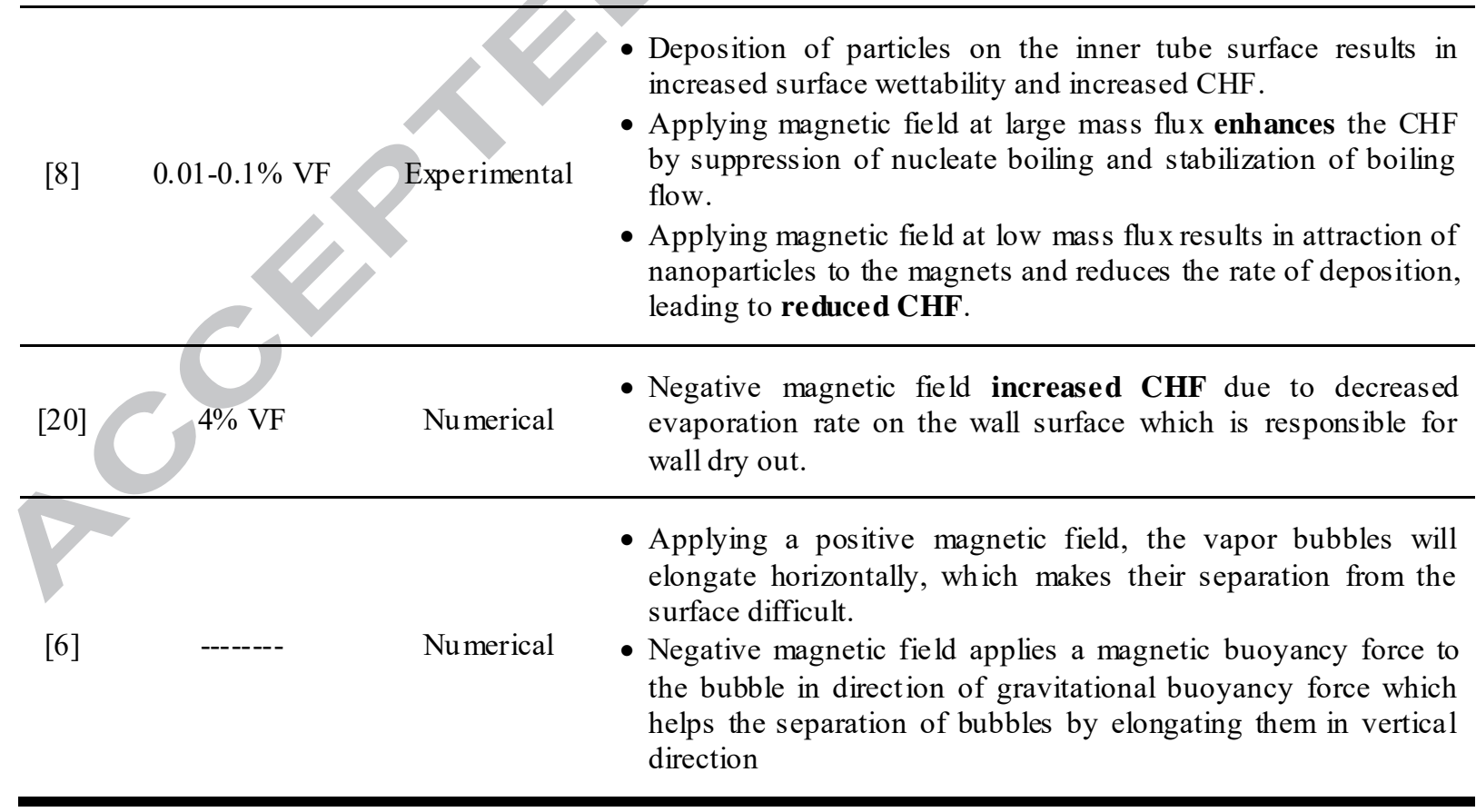




\section{Experime ntal setup}

A 50- $\mu \mathrm{m}$ copper wire, transiently heated with a constant current was used to investigate boiling heat transfer in the ferrofluid. The measurement cell designed for this experiment includes a circular channel with $50 \mathrm{~mm}$ length and $8 \mathrm{~mm}$ diameter with $1 \mathrm{~mm}$ thick acrylic wall. The copper wire passing through the centre of the channel is soldered to thin copper tapes covering both ends of the channel. Two tiny holes were drilled at the top and bottom of the channel, one for fluid injection and the other one for bubbles to escape. Lead wires were soldered to the thin copper tapes at the two ends of the channel to connect the microwire to power supply and multimeter. A KEITHLEY 2200 power supply was used to apply a constant current to the microwire (and generate heat via Joule heating), a KEITHLEY 2000 multimeter was used to measure the voltage, and a LabView ${ }^{\mathrm{TM}}$ program was designed to record the data of voltage vs. time. An ISOTECH RS422 temperature bath was used to ensure uniform temperature around the measurement cell. A constant current (DC) is supplied to the wire and the voltage is measured using the multimeter and recorded over a specified period of time. Measurement time was limited to maximum $20 \mathrm{~s}$ with $0.05 \mathrm{~s}$ time increments and the currents supplied were limited to maximum 3.5 A. All experiments were performed at an initial bath temperature of $75^{\circ} \mathrm{C}$. The resistance of the wire is calculated using Ohm's law $\left(R=\frac{V}{I}\right)$. The system was calibrated to find the temperature coefficient of resistance (TCR) of the wire. Using this calibration, the calculated transient resistance of the wire was converted into a space-averaged transient wire temperature as:

$$
T=\frac{\left(\frac{R}{R_{0}}-1\right)}{T C R}
$$

To investigate the relative importance of various parameters on measured outputs, an uncertainty analysis was performed. All calculations for propagation and combination were done based on standard uncertainties $(k=2)$. The uncertainty in the length of the cell measured for 5 different cells was $\pm 1 \mathrm{~mm}$. The uncertainty in the measured temperature of the wire owing to the uncertainty in the calibrated TCR of the wire is around $2 \%$. The uncertainties in the supplied DC current and measured voltage are $0.05 \%$ and $0.001 \%$, respectively (according to the equipment manual), which has been neglected in this analysis. The initial bath temperature was estimated to have $0.5^{\circ} \mathrm{C}$ uncertainty, based on the comparison with the reference thermometer. The radius of the measurement cell was measured to have $5 \%$ uncertainty and other parameters considered in this analysis were assumed to have $1 \%$ uncertainty. Uncertainty analysis is summarised in Table 2. A schematic of the measurement setup is shown in Figure 1. More details about design and calibration of the setup are given in $[21]$. 
Table 2 Uncertainty analys is

\begin{tabular}{cccccc}
\hline Input & Symbol & Unit & Uncertainty & $\boldsymbol{q}$ (Exp) & $\boldsymbol{q}$ (Rohsenow) \\
\hline Specific heat & $C_{p}$ & $\mathrm{~J} / \mathrm{kg} . \mathrm{K}$ & $1 \%$ & - & $3 \%$ \\
Viscosity & $\mu$ & $\mathrm{Pa.s}$ & $1 \%$ & - & $1 \%$ \\
Density & $\rho$ & $\mathrm{Kg} / \mathrm{m}^{3}$ & $1 \%$ & - & $0.5 \%$ \\
Temperature & $T$ & ${ }^{\circ} \mathrm{C}$ & $2 \%$ & - & $6 \%$ \\
Length & $L$ & $\mathrm{~m}$ & $2 \%$ & - & - \\
Cell radius & $r_{\text {cell }}$ & $\mathrm{m}$ & $5 \%$ & $0.05 \%$ & - \\
Voltage & $V$ & $\mathrm{~V}$ & $0.05 \%$ & $0.01 \%$ & - \\
Current & $I$ & $\mathrm{~A}$ & $0.01 \%$ & $0.05 \%$ & $6.7 \%$ \\
Combined & & & & & - \\
\hline
\end{tabular}

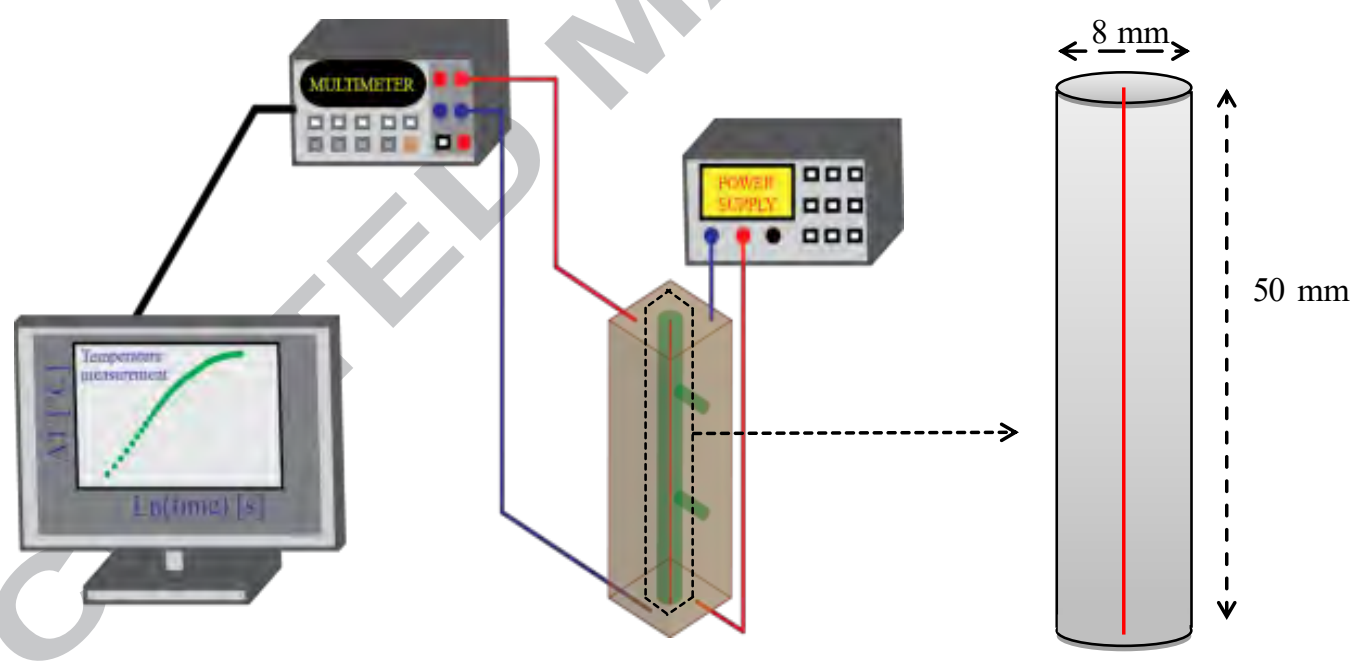

Figure 1 Schematic of the experiment setup

\section{Results and discussion}

In the present work, the boiling heat transfer of ferrofluid when temperature of the fluid in contact with the wire reaches above $100{ }^{\circ} \mathrm{C}$ is studied. The sample used in this experiment is a $2 \%$ volume concentration ferrofluid with average nanoparticles diameter of $10 \mathrm{~nm}$, provided by Ferrotec $^{\mathrm{TM}}$. 


\subsection{Thermomagnetic convection below boiling point}

Firstly, to evaluate the superiority of ferrofluid over water in heat transfer, the temperature rise of the wire in ferrofluid was compared to the one in deionized water over a short period of time, when 1.5 A is supplied to the microwire (Fig.2).

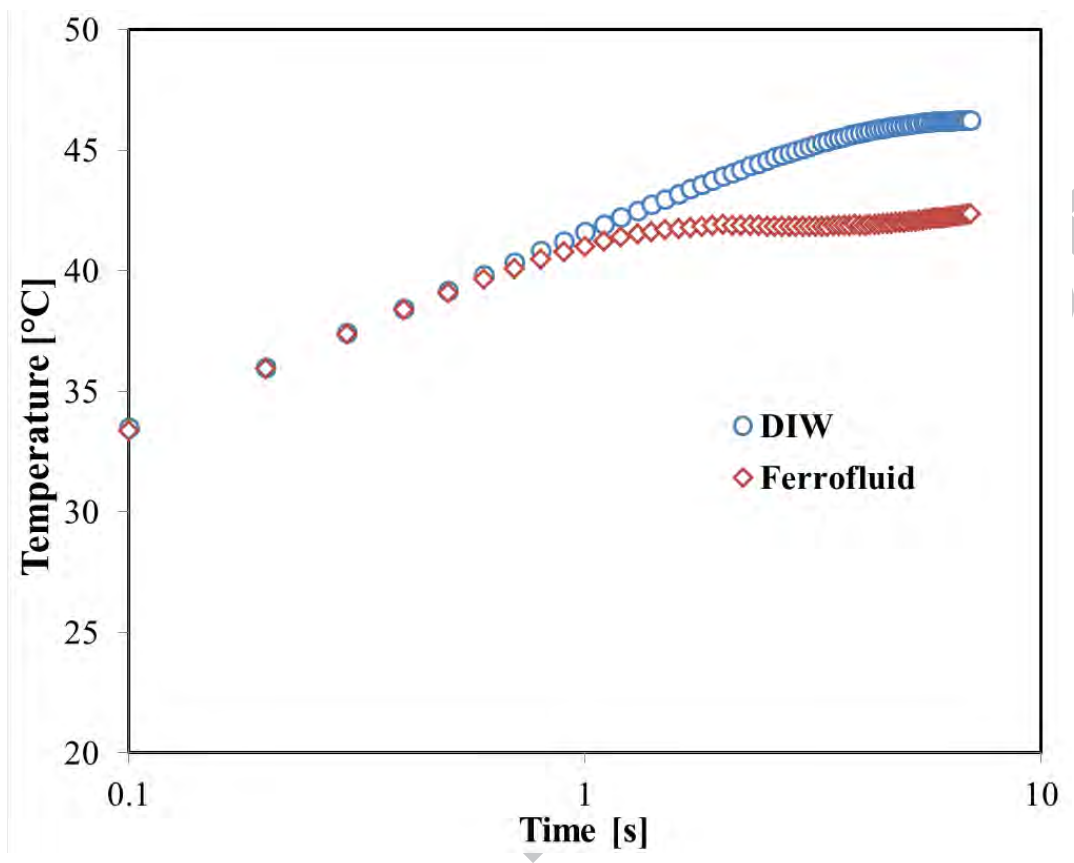

Figure 2 Temperature rise of the wire over 7 seconds when $1.5 \mathrm{~A}$ is supplied (at $20^{\circ} \mathrm{C}$ in itial bath temperature).

As is shown in Figure 2, the two overlapping lines separate after $1.4 \mathrm{~s}$ where the slope of the line for ferrofluid significantly drops. This behaviour can be attributed to "thermomagnetic convection" occurrence [22]. Thermomagnetic convection is another type of free convective heat transfer which arises in a magnetic field with temperature gradients due to temperature dependence of the magnetic susceptibility of the ferrofluid. The heat transfer enhancement of a ferrofluid around a vertical current carrying wire rather than deionized water due to thermomagnetic convection has been theoretically explained in [23]. When a constant current is supplied to the microwire, a non-uniform magnetic field is induced around the wire. The magnetic field applies a body force $f=\nabla(M . B)$ to the ferrofluid which induces a flow in direction of decreasing susceptibility, toward the wire resulting in thermomagnetic convection. In the above equation $M$ denotes the magnetization and $B$ is the magnetic flux density. The onset of thermomagnetic convection has been studied and correlated in [22]. Figure 2 is clearly consistent with the findings of [23] concerning convection heat transfer enhancement from a current-carrying wire using ferrofluid.

\subsection{Boiling heat transfer of ferrofluid}

To study the boiling heat transfer of the ferrofluid, higher currents than those used in [22] were applied to the microwire to increase the temperature of the hotwire above the normal boiling point of water. To validate the experimental procedure, the boiling curve for DIW was compared with Rohsenow's correlation [24] and demonstrated in Figure 2, where acceptable 
agreement was observed between the experiment and correlation. In Figure 3, the power supplied to the wire is calculated from the resistance of the wire and the current supplied $\left(R I^{2}\right)$. Figure 4 compares the temperature rise of the hotwire in both ferrofluid and DIW above the boiling point of water for different currents supplied to the wire for a period of $10 \mathrm{~s}$. The initial bath temperature was set to $75^{\circ} \mathrm{C}$ since above that the acrylic cell deforms.

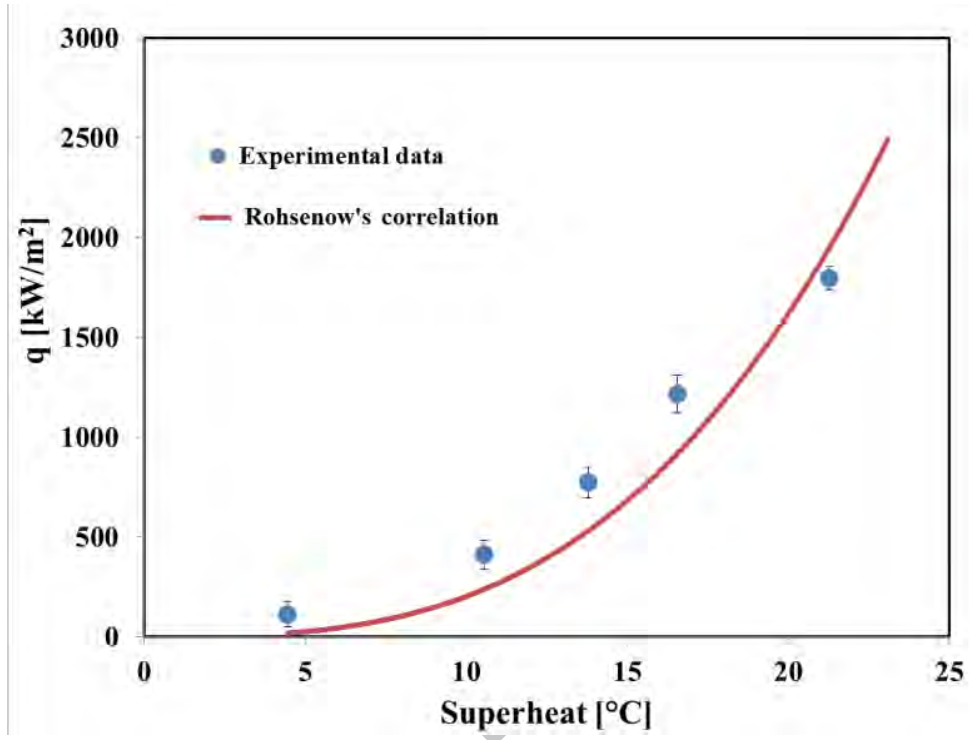

Figure 3 Apparatus validation, heat flux as a function of superheat value.

It is shown in Figures 4a-c that the temperature of the wire in DIW tends to reach steady-state at around $110{ }^{\circ} \mathrm{C}$, while in ferrofluid it exhibits a drastic rise after a short time of $3.3 \mathrm{~s}, 1.1 \mathrm{~s}$ and $0.75 \mathrm{~s}$ when $2.5 \mathrm{~A}, 3 \mathrm{~A}$ and $3.5 \mathrm{~A}$ currents are supplied, respectively. This sudden drastic temperature rise happens when the temperature of the fluid at the vicinity of the wire is about $113^{\circ} \mathrm{C}, 135^{\circ} \mathrm{C}$ and $149{ }^{\circ} \mathrm{C}$, respectively, and is so significant that the temperature of the wire reaches to more than $215^{\circ} \mathrm{C}$ in $10 \mathrm{~s}$ for the case of $2.5 \mathrm{~A}$ supplied. For the cases when $3 \mathrm{~A}$ and $3.5 \mathrm{~A}$ is supplied, the temperature of the wire reaches to aro und $397{ }^{\circ} \mathrm{C}$ in only $2.45 \mathrm{~s}$ and 1.10 $\mathrm{s}$, respectively, and then burns out. Figure 4 clearly shows that ferrofluid is unexpectedly not a good option for boiling heat transfer enhancement for the conditions considered. 

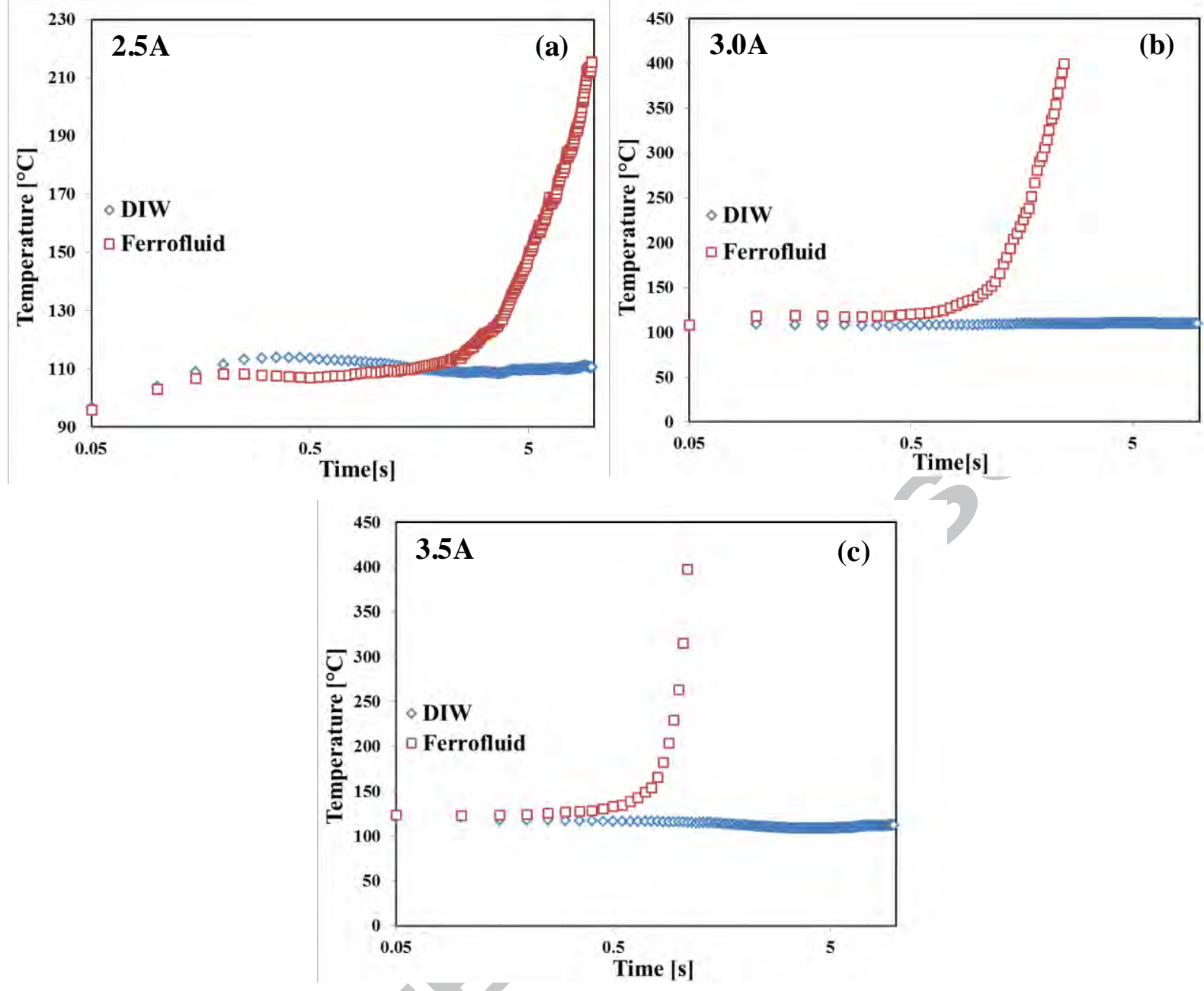

Figure 4 Temperature rise of the hotwire when a) $2.5 \mathrm{~A} \mathrm{~b}$ ) $3 \mathrm{~A} \mathrm{c)} 3.5 \mathrm{~A}$ is supplied.

The low heat removal of ferrofluid can be explained in relation to deposition of nanoparticles on the microwire. As Kim et al [25] explains, during the boiling of nanofluid, a nanocoating forms on the heated surface as the microlayer growing under the vapor layer evaporates, leaving behind nanoparticles adhered to the wire. In contrast with observations of Sarafraz et al [26] who report that the coating layer enhances the heat transfer of the nanofluid by changing the number of micro-cavities on heated surface and the surface wettability, the results in Fig. 4 for the ferrofluid show a degradation of heat transfer. It is conceivable that the particles deposited on the wire form a porous layer with cavity holes which become filled with water vapour preventing effective heat transfer from the wire.

Even without consideration of boiling heat transfer, the coating of ferromagnetic particles on the wire provides additional thermal resistance between the wire and the fluid. The validity of this claim was examined by studying the effect of coating layer on temperature rise of the wire. First the temperature rise of the wire immersed in DIW for 1.5 A being supplied was measured for $20 \mathrm{~s}$. Then the experiment was repeated with $2.4 \mathrm{~A}$ with measurement cell filled with ferrofluid to make a coating layer of nanoparticles on the surface of wire (Fig 6c). Finally, the temperature rise of wire in DIW was measured again but this time with the coated wire. Figure 5 shows the temperature rise of both original wire and coated wire immersed in DIW. Better 
heat transfer from the wire is observed for the original bare wire, which confirms the claim that the porous coating acts as an insulation layer even without consideration of boiling heat transfer. In other words when the temperature of the fluid at the vicinity of the wire becomes larger than the boiling temperature of water, the water molecules in the region evaporate, leaving the magnetic particles on the wire surface. Agglomeration of these particles on the wire forms a porous layer with lower thermal conductivity than ferrofluid which also prevents effective convection between ferrofluid and wire resulting in degraded heat transfer.

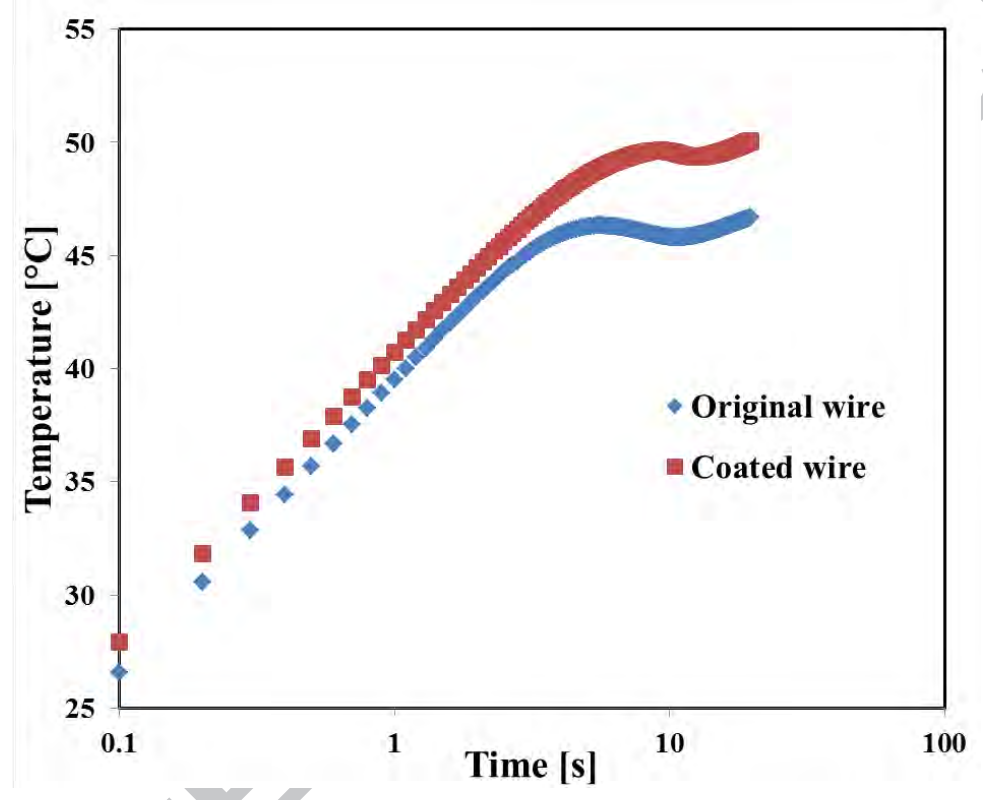

Figure 5 Comparis on of the temperature rise (for 1.5 A) of an uncoated wire and a wire coated with ferro magnetic particles by first being heated in ferrofluid using an electric current of 2.4 amps for 10 seconds

\subsection{Deposition of nanoparticles on microwire}

To better understand the mechanism behind the poor boiling heat transfer performance of the ferrofluid, deposition of the nanoparticles was studied using SEM images. A new wire was used for each experiment. First, the microwire was immersed in ferrofluid for 24 hours without an electrical current, where no deposition of particles on the surface of wire was observed. Figure 6a shows an SEM image of the wire after a constant current of 2 A was supplied for 10 $\mathrm{s}$, where still no particles were deposited on the wire surface. Deposition of particles was observed when the current was increased to 2.4 A (Fig.6b) where a porous layer was formed around the wire after 10 seconds of heating. 

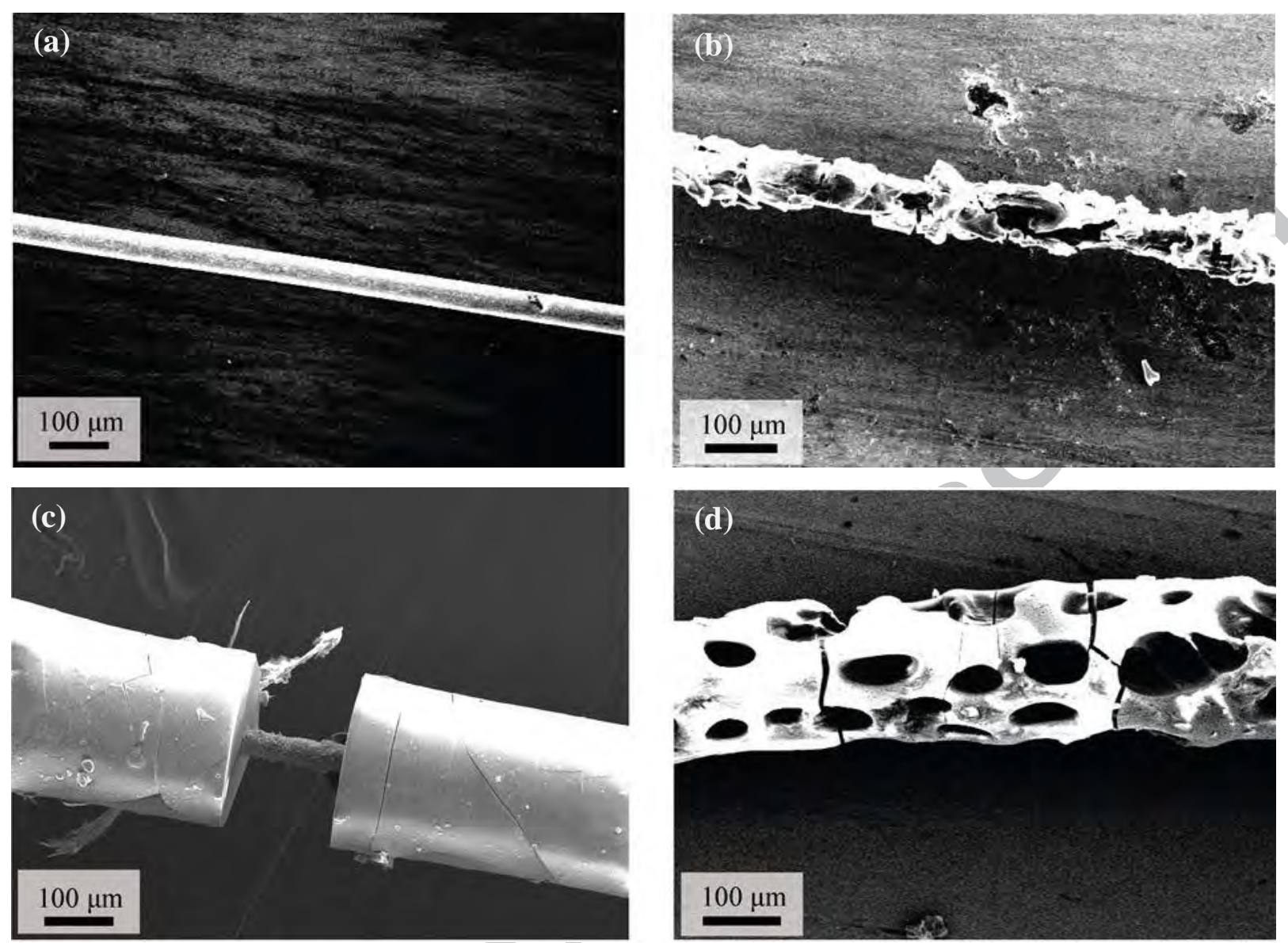

Figure 6 SEM images of a) $2 \mathrm{~A}$ for $10 \mathrm{~s} \mathrm{b)} 2.4 \mathrm{~A}$ for $10 \mathrm{~s} \mathrm{c)} 2.4 \mathrm{~A}$ for $20 \mathrm{~s}$ and d) $3.3 \mathrm{~A}$ for $0.7 \mathrm{~s}$.

The morphology, thickness and consequently thermal resistance of the coating layer depend on the current and the time that current is being supplied and the concentration of nanoparticles in ferrofluid. To show the effect of time, 2.4 A was supplied again, this time for $20 \mathrm{~s}$ (Fig. 6c). It is shown that the diameter of the coated wire has increased from $\sim 89 \mu \mathrm{m}$ after $10 \mathrm{~s}$ to $\sim 236 \mu \mathrm{m}$ after $20 \mathrm{~s}$. This coating layer of nanoparticles is almost four times thicker than the bare wire. The reason for the continuing deposition of particles on the wire is that, as thermomagnetic convection happens, circulating flows are induced in the ferrofluid that circulate nanoparticles and bring them to the vicinity of the wire. This could be the main difference when using ferrofluid rather other types of nanofluid. To study the effect of current on the deposition of particles, the current was increased to $3.5 \mathrm{~A}$, where the wire broke after $0.7 \mathrm{~s}$ only. Figure $6 \mathrm{~d}$ shows that, surprisingly, the diameter of the coated wire after only $0.7 \mathrm{~s}$ is about $205 \mu \mathrm{m}$. Comparing figure $6 \mathrm{c}$ and $6 \mathrm{~d}$ it can be concluded that although in both cases the coating layers have almost same thickness, but for the case of $3.3 \mathrm{~A}$, the porous layer is less structured. The reason is considered to be due to both the short time of the heating, where nanoparticles did not have enough time to form a homogenous layer, and also vigorous nucleation boiling due to the high current supplied. 
Comparing Figures $6 \mathrm{a}$ and $6 \mathrm{~b}$ it can be concluded that this deposition is not simply an effect of the magnetic force, but the boiling of the ferrofluid. Figure 7 shows the temperature-time history of the wire for the currents supplied. When a low current $(2 \mathrm{~A})$ is supplied for a short time (10 s), the magnetic force is large enough to make thermomagnetic convection occur [23] but the temperature has not reached the boiling point of water at atmospheric press ure. When a large enough current $(2.4 \mathrm{~A})$ is supplied, the temperature of the fluid in the vicinity of the wire reaches above the water boiling point before the thermomagnetic convection occurs, resulting in evaporation of the fluid molecules. When fluid molecules evaporate, the remaining nanoparticles in the region adhere to the wire as shown in Figures 6b-d.

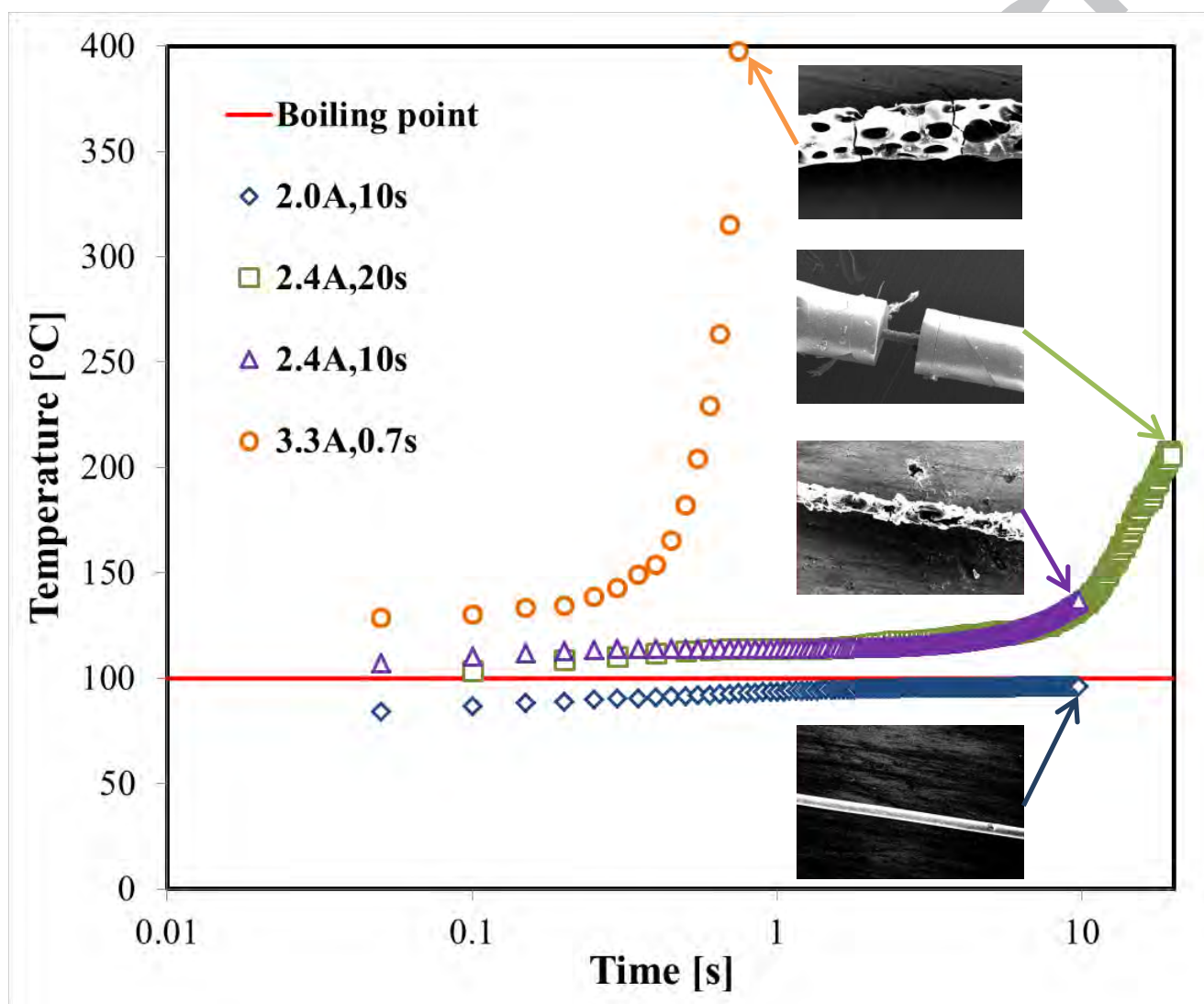

Figure 7 Temperature-time history of the wire when different currents are supplied for different times having $75^{\circ} \mathrm{C}$ initial bath temperatures.

\subsection{Effect of concentration on deposition of particles}

Figure 8 shows the deposition of nanoparticles on the heated wire immersed in ferrofluid with three different volume concentrations of $2 \%, 0.4 \%$ and $0.2 \%$ when $2.2 \mathrm{~A}$ was supplied for $20 \mathrm{~s}$. As expected, the coating around the wire is much thicker for the $2 \%$ ferrofluid with a coated wire diameter of $\sim 151 \mu \mathrm{m}$, while the average measured diameter is only $\sim 72 \mu \mathrm{m}$ and $\sim 67 \mu \mathrm{m}$ for $0.4 \%$ and $0.2 \%$ ferrofluids, respectively. The rate of deposition of particles (average diameter/time) for the $2 \%$ concentration ferrofluid is 6.5 times that of the highly diluted fluid with $0.2 \%$ concentration, while its concentration is 9 times bigger. This may be attributed to the earlier onset of boiling for the diluted fluid since its properties are very similar to DIW. 

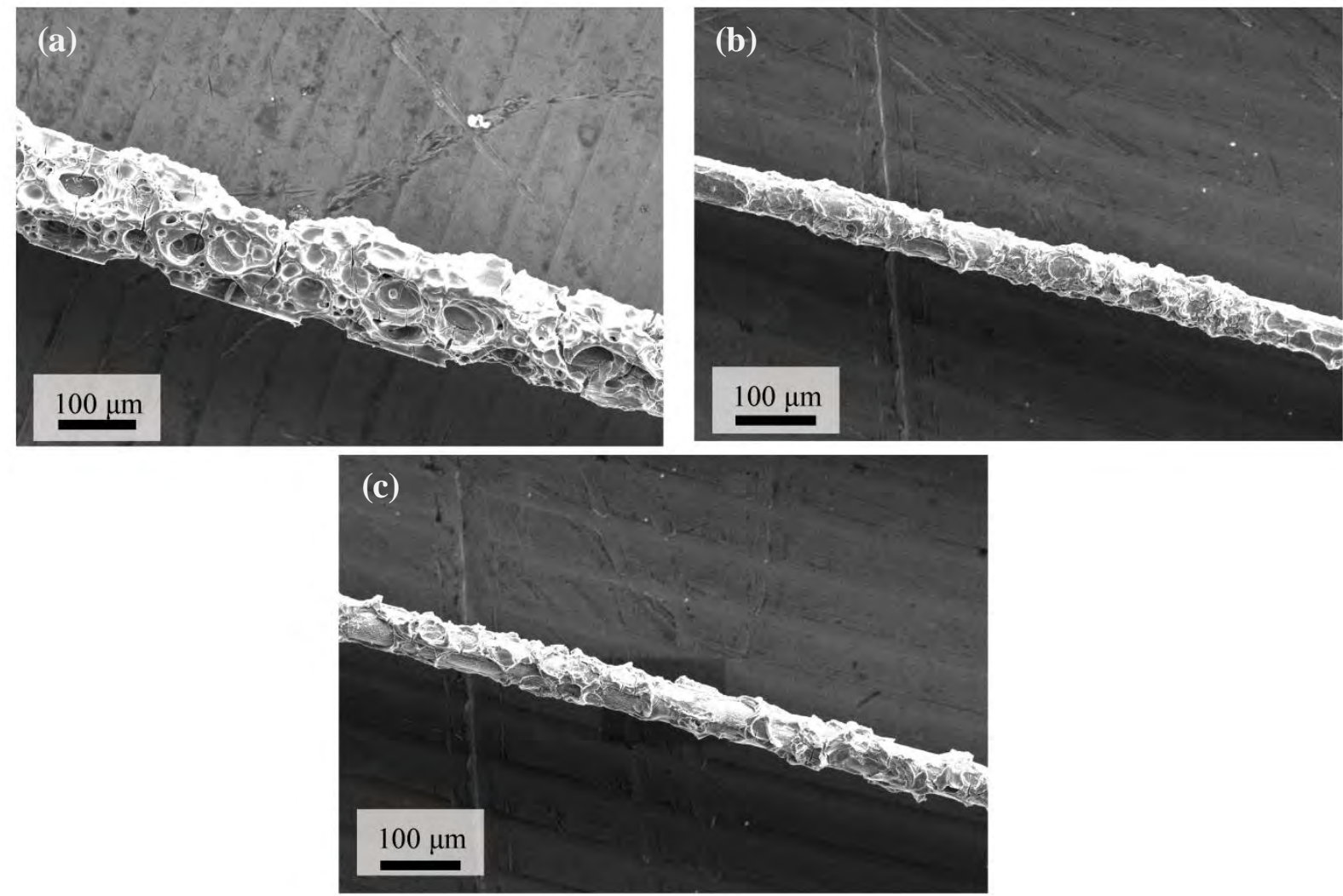

Figure 8 SEM images of the coated wires in ferrofluid with different volume concentrations of a) $2 \%$ b) $0.4 \%$ and c) $0.2 \%$.

\section{Conclusion}

Boiling heat transfer for ferrofluid around a current carrying wire was studied. It was shown that, in contrast to the findings of other studies, deposition of particles on the wire deteriorates the boiling heat transfer from a single wire immersed in ferrofluid. The rate of particle deposition depends on the power being supplied, time and concentration of the ferrofluid. For the case of conventional non-magnetic nanofluids, only particles in the vicinity of the heated surface adhere to the surface, while for the case of ferrofluid the induced magnetic field around the current carrying wire enhances the deposition rate.

\section{Acknowledgment}

NT Nguyen acknowledges funding support of the Australian Research Council for the project LP150100153

\section{References}

[1] J. Wang, F.-C. Li, X.-B. Li, On the mechanism of boiling heat transfer enhancement by surfactant addition, International Joumal of Heat and Mass Transfer, 101 (2016) 800-806. 
[2] A.K. Sadaghiani, N.S. Saadi, S.S. Parapari, T. Karabacak, M. Keskinoz, A. Koşar, Boiling heat transfer performance enhancement using micro and nano structured surfaces for high heat flux electronics cooling systems, Applied Thermal Engineering, (2017).

[3] F. Fadaei, M. Shahrokhi, A.M. Dehkordi, Z. Abbasi, Heat transfer enhancement of Fe 304 ferrofluids in the presence of magnetic field, Journal of Magnetism and Magnetic Materials, 429 (2017) 314-323.

[4] W. Cherief, Y. Avenas, S. Ferrouillat, A. Kedous-Lebouc, L. Jossic, M. Petit, Parameters affecting forced convection enhancement in ferrofluid cooling systems, Applied Thermal Engineering, 123 (2017) 156-166.

[5] L. Xu, X. Peng, Fundamental analysis of boiling heat transfer of magnetic fluids in a magnetic field, Heat Transfer-Asian Research, 31(2) (2002) 69-75.

[6] M. Mohammadpourfard, H. Aminfar, M. Sahraro, Numerical simulation of nucleate pool boiling on the horizontal surface for ferrofluid under the effect of non-uniform magnetic field, Heat and Mass Transfer, 50(8) (2014) 1167-1176.

[7] A. Vatani, P.L. Woodfield, D.V. Dao, A survey of practical equations for prediction of effective thermal conductivity of spherical-partide nanofluids, Journal of Molecular Liquids, 211 (2015) 712733.

[8] H. Aminfar, M. Mohammadpourfard, R. Maroofiazar, Experimental study on the effect of magnetic field on critical heat Flux of ferrofluid flow boiling in a vertical annulus, Experimental Thermal and Fluid Science, 58 (2014) 156-169.

[9] H.H. Khoshmehr, A. Saboonchi, M.B. Shafii, N. Jahani, The study of magnetic field implementation on cylinder quenched in boiling ferro-fluid, Applied Thermal Engineering, 64(1) (2014) 331-338.

[10] A. Abdollahi, M.R. Salimpour, N. Etesami, Experimental analysis of magnetic field effect on the pool boiling heat transfer of a ferrofluid, Applied Thermal Engineering, 111 (2017) 1101-1110.

[11] L. Junhong, G. Jianming, L. Zhiwei, L. Hui, Experiments and mechanism analysis of pool boiling heat transfer enhancement with water-based magnetic fluid, Heat and mass transfer, 41(2) (2004) 170-175.

[12] S.N. Shoghl, M. Bahrami, M. Jamialahmadi, The boiling performance of ZnO, $\alpha$-Al 203 and MWCNTs/water nanofluids: An experimental study, Experimental Thermal and Fluid Science, 80 (2017) 27-39.

[13] I.C. Bang, S.H. Chang, Boiling heat transfer performance and phenomena of Al 20 3-water nanofluids from a plain surface in a pool, International Journal of Heat and Mass Transfer, 48(12) (2005) 2407-2419.

[14] S.K. Das, N. Putra, W. Roetzel, Pool boiling characteristics of nano-fluids, International journal of heat and mass transfer, 46(5) (2003) 851-862.

[15] L.L. Manetti, M.T. Stephen, P.A. Beck, E.M. Cardoso, Evaluation of the heat transfer enhancement during pool boiling using low concentrations of Al 20 3-water based nanofluid, Experimental Thermal and Fluid Science, (2017).

[16] C.-C. Hsu, M.-R. Lee, C.-H. Wu, P.-H. Chen, Boiling heat transfer enhancement by impurities depositon of tap water, Experimental Thermal and Fluid Science, (2017).

[17] M. Shojaeian, M.-M. Yildizhan, Ö. Coşkun, E. Ozkalay, Y. Tekşen, M.A. Gulgun, H.F.Y. Acar, A. Koşar, Investigation of change in surface morphology of heated surfaces upon pool boiling of magnetic fluids under magnetic actuation, Materials Research Express, 3(9) (2016) 096102.

[18] M. Kole, T. Dey, Investigations on the pool boiling heat transfer and critical heat flux of $\mathrm{ZnO}$ ethylene glycol nanofluids, Applied Thermal Engineering, 37 (2012) 112-119.

[19] J. Ham, H. Kim, Y. Shin, H. Cho, Experimental investigation of pool boiling characteristics in Al 20 3 nanofluid according to surface roughness and concentration, International Journal of Thermal Sciences, 114 (2017) 86-97.

[20] H. Aminfar, M. Mohammadpourfard, R. Maroofiazar, Numerical study of non-uniform magnetic fields effects on subcooled nanofluid flow boiling, Progress in Nuclear Energy, 74 (2014) 232-241. 
[21] A. Vatani, P.L. Woodfield, D.V. Dao, A miniaturized transient hot-wire device for measuring thermal conductivity of non-conductive fluids, Microsystem Technologies, 22(10) (2016) 2463-2466.

[22] P.W. A. Vatani, N.T. Nguyen, D. Dao, Onset of thermomagnetic convection around a vertically oriented hot-wire in ferrofluid, Journal of Magnetism and Magnetic materials, (2017).

[23] A. Vatani, P.L. Woodfield, N.-T. Nguyen, D.V. Dao, Thermomagnetic Convection Around a CurrentCarrying Wire in Ferrofluid, Journal of Heat Transfer, 139(10) (2017) 104502.

[24] W.M. Rohsenow, A method of correlating heat transfer data for surface boiling of liquids, Cambridge, Mass.: MIT Division of Industrial Cooporation,[1951], 1951.

[25] S.J. Kim, I.C. Bang, J. Buongiorno, L. Hu, Surface wettability change during pool boiling of nanofluids and its effect on critical heat flux, International Journal of Heat and Mass Transfer, 50(19) (2007) 4105-4116.

[26] M. Sarafraz, T. Kiani, F. Hormozi, Critical heat flux and pool boiling heat transfer analysis of synthesized zirconia aqueous nano-fluids, International Communications in Heat and Mass Transfer, 70 (2016) 75-83. 


\section{Highlights}

- Transient boiling heat transfer from a vertically-heated wire in ferrofluid was experimentally studied.

- Particle deposition on the wire was found to suppress the boiling heat transfer.

- Effective parameters on particle deposition rate were studied. 


\section{Accepted Manuscript}

Degraded boiling heat transfer from hotwire in ferrofluid due to particle deposition

Ashkan Vatani, Peter Lloyd Woodfield, Toan Dinh, Hoang-Phuong Phan, NamTrung Nguyen, Dzung Viet Dao

PII: S1359-4311(17)36900-4

DOI: https://doi.org/10.1016/j.applthermaleng.2018.06.064

Reference: ATE 12335

\section{APPLIED}

THERMAL ENGINEERING

\section{Applied Thermal Engineering}

Received Date:

29 October 2017

Revised Date:

14 June 2018

Accepted Date:

20 June 2018

Please cite this article as: A. Vatani, P. Lloyd Woodfield, T. Dinh, H-P. Phan, N-T. Nguyen, D. Viet Dao, Degraded boiling heat transfer from hotwire in ferrofluid due to particle deposition, Applied Thermal Engineering (2018), doi: https://doi.org/10.1016/j.applthermaleng.2018.06.064

This is a PDF file of an unedited manuscript that has been accepted for publication. As a service to our customers we are providing this early version of the manuscript. The manuscript will undergo copyediting, typesetting, and review of the resulting proof before it is published in its final form. Please note that during the production process errors may be discovered which could affect the content, and all legal disclaimers that apply to the journal pertain. 